\title{
Assessing the nutritional status of hospitalized elderly
}

\author{
Nur Adilah Shuhada \\ Abd Aziz \\ Nur Islami Mohd \\ Fahmi Teng \\ Mohd Ramadan Abdul \\ Hamid \\ Nazrul Hadi Ismail \\ Department of Nutrition and \\ Dietetics, Faculty of Health Sciences, \\ Universiti Teknologi MARA, Puncak \\ Alam, Malaysia
}

Correspondence: Nur Islami Mohd Fahmi Teng

Faculty of Health Sciences, Universiti Teknologi MARA, Cawangan Selangor, Kampus Puncak Alam, 42300 Puncak Alam, Malaysia

Tel +60332584540

Fax +60332584599

Email nurislami@puncakalam.uitm.edu.my
This article was published in the following Dove Press journal:

Clinical Interventions in Aging

4 October 2017

Number of times this article has been viewed

Purpose: The increasing number of elderly people worldwide throughout the years is concerning due to the health problems often faced by this population. This review aims to summarize the nutritional status among hospitalized elderly and the role of the nutritional assessment tools in this issue.

Methods: A literature search was performed on six databases using the terms "malnutrition", "hospitalised elderly", "nutritional assessment", "Mini Nutritional Assessment (MNA)", "Geriatric Nutrition Risk Index (GNRI)", and "Subjective Global Assessment (SGA)".

Results: According to the previous studies, the prevalence of malnutrition among hospitalized elderly shows an increasing trend not only locally but also across the world. Under-recognition of malnutrition causes the number of malnourished hospitalized elderly to remain high throughout the years. Thus, the development of nutritional screening and assessment tools has been widely studied, and these tools are readily available nowadays. SGA, MNA, and GNRI are the nutritional assessment tools developed specifically for the elderly and are well validated in most countries. However, to date, there is no single tool that can be considered as the universal gold standard for the diagnosis of nutritional status in hospitalized patients.

Conclusion: It is important to identify which nutritional assessment tool is suitable to be used in this group to ensure that a structured assessment and documentation of nutritional status can be established. An early and accurate identification of the appropriate treatment of malnutrition can be done as soon as possible, and thus, the malnutrition rate among this group can be minimized in the future.

Keywords: malnutrition in elderly, nutritional assessment, MNA, GNRI, SGA

\section{Introduction}

The United Nations defines elderly as those aged 60 years old and above, and the definition also applies to the Malaysian population as stated in the National Policy of the Elderly. ${ }^{1}$ The aging phenomenon is common around the world, and the aging population continuously increases in number from time to time. It is estimated that in between 2015 and 2030, the population will grow by 56\%, from 901 million to 1.4 billion, and by 2050, the population will grow more than double its size in 2015 which could possibly reach up to 2.1 billion. ${ }^{1}$ In Malaysia, however, the department of statistics reported that $8.2 \%$ of the population were accounted as elderly in 2012 , and by 2030 , it is expected that Malaysia will be one among the aging nations with older population reaching about more than $15 \%$ of the total Malaysian population. ${ }^{2}$ This rapid demographic transition was found to be due to several factors, such as declining fertility rates, lower infant mortality, and increasing survival at older age. ${ }^{3}$ Thus, as this aging population grows from time to time, it is crucial to attend issues related to this group. Health, independency, and quality of life of elderly depend on their nutritional 
well-being. ${ }^{4}$ Therefore, early prevention, identification of high-risk individuals, and appropriate interventions should be addressed to this group. ${ }^{5}$ This paper reviews the malnutrition and the role of nutritional assessment tools among the hospitalized elderly population.

\section{Methods}

A literature review was done by using six databases, namely, PubMed, Elsevier, ScienceDirect, Google Scholar, SpringerLink, and ClinicalKey. Publications between 2007 and 2016 in the English language were used for this review. The terms used to search the related articles were "malnutrition", "hospitalised elderly", "nutritional assessment", "Mini Nutritional Assessment (MNA)", "Geriatric Nutrition Risk Index (GNRI)", and "Subjective Global Assessment (SGA)". The full articles were obtained if their abstracts explained on malnutrition referring to undernutrition, factors and effect of malnutrition, nutritional screening and assessment, or validity and comparison of nutritional assessment tools within the context of hospitalized elderly population.

\section{Discussion}

\section{Elderly and malnutrition}

Cancer, heart disease, dementia, and other morbid conditions are found to have a relationship with the nutritional status of the elderly aged 65 years and above. ${ }^{6}$ Aging process is believed to be one of the causes of malnutrition, which eventually affects the nutritional status of the elderly. ${ }^{7}$ The American Society for Parenteral and Enteral Nutrition (ASPEN) defined malnutrition as

an acute, subacute or chronic state of nutrition, in which varying degrees of overnutrition or undernutrition with or without inflammatory activity have led to a change in body composition and diminished function. ${ }^{8}$
According to this definition, malnutrition can be referred to as both over- and undernourished. Although the prevalence of overnutrition among elderly in the developing countries is increasing due to their adverse development and changes in the eating habit of the elderly, undernutrition, in general, is still the main issue of concern. Therefore, within the context of this review, malnutrition refers to undernutrition unless otherwise specified.

\section{Prevalence of malnourished hospitalized elderly}

The prevalence of malnutrition across the world, even in the well-developed countries including the US, shows an increasing trend from time to time. ${ }^{9}$ In Asia however, it was found that a ranged of $16 \%-78 \%$ of hospitalized elderly are malnourished (including those at risk of malnutrition) in between 2005 to $2012 .^{9}$ This percentage range is similar to that in the UK, where a study showed that 29\%-61\% of hospitalized elderly are malnourished, ${ }^{10}$ while another study stated that the UK has $58 \%$ of malnourished hospitalized elderly. ${ }^{11}$

Regarding Malaysia, the prevalence of malnutrition among the elderly population, in general, is similar to other countries. A study conducted in Malaysia showed that among 181 subjects, $55.2 \%$ were malnourished of which $18.0 \%$ of the subjects had a body mass index (BMI) of $<18.5 \mathrm{~kg} / \mathrm{m}^{2}$. In addition, based on the anthropometric measures on the body composition of the patients, it was found that $16 \%-26 \%$ of the subjects had muscle wasting. ${ }^{12}$ Meanwhile, a local study in another hospital in Malaysia had found that $21 \%$ of elderly patients are malnourished as shown by the Global Indicator of Malnutrition (GIM). ${ }^{13}$ Tables 1 and 2 show the summary of the recent studies on the prevalence of malnourished elderly internationally and in Asia, respectively.

The difference in the prevalence of malnutrition across the world as stated in Tables 1 and 2 may be due to different

Table I Prevalence of malnourished hospitalized elderly internationally

\begin{tabular}{|c|c|c|c|c|c|}
\hline Study & Country & Method & $\begin{array}{l}\text { Sample } \\
\text { size }\end{array}$ & Criteria for malnutrition & Findings \\
\hline Drescher et $\mathrm{al}^{57}$ & Switzerland & Cross-sectional study & 104 & $\begin{array}{l}\text { MNA } \\
\text { NRS-2002 }\end{array}$ & $\begin{array}{l}22 \% \text { malnourished } \\
34 \% \text { moderate-to-severe } \\
\text { risk of malnutrition }\end{array}$ \\
\hline Amaral et $\mathrm{al}^{58}$ & Portugal & Cross-sectional study & 404 & $\begin{array}{l}\text { Anthropometry measurement: } \mathrm{BMI}<18.5 \mathrm{~kg} / \mathrm{m}^{2} \text { or, } \\
\mathrm{BMI}<20.0 \mathrm{~kg} / \mathrm{m}^{2} \text { and Triceps skinfold thickness or } \\
\text { mid-arm muscle circumference values were under } \\
\text { the I } 5 \text { th centile }\end{array}$ & II.6\% malnourished \\
\hline Vanderwee et $\mathrm{al}^{59}$ & Belgium & Cross-sectional study & 2,329 & MNA & $33 \%$ malnourished \\
\hline Abd-Al-Atty et $\mathrm{al}^{34}$ & Cairo & Cross-sectional study & 230 & MNA-SF-Arabic & $44.8 \%$ malnourished \\
\hline Agarwal et $\mathrm{al}^{60}$ & $\begin{array}{l}\text { Australia and } \\
\text { New Zealand }\end{array}$ & $\begin{array}{l}\text { Multisite cross- } \\
\text { sectional study }\end{array}$ & 3,122 & $\begin{array}{l}\text { SGA B }+C \text { and } B M I<I 8.5 \mathrm{~kg} / \mathrm{m}^{2} \text { or unintentional } \\
\text { weight loss with suboptimal dietary intake (based } \\
\text { on ICD-I0-AM) }\end{array}$ & $\begin{array}{l}32 \% \text { malnourished } \\
\text { (undernutrition) }\end{array}$ \\
\hline
\end{tabular}

Abbreviations: MNA, Mini Nutritional Assessment; NRS-2002, Nutritional Risk Screening-2002; BMI, body mass index; MNA-SF, Mini Nutritional Assessment Short Form; SGA, Subjective Global Assessment; ICD-IO-AM, International Statistical Classification of Disease and Related Health Problem. 
Table 2 Prevalence of malnourished hospitalized elderly in Asia

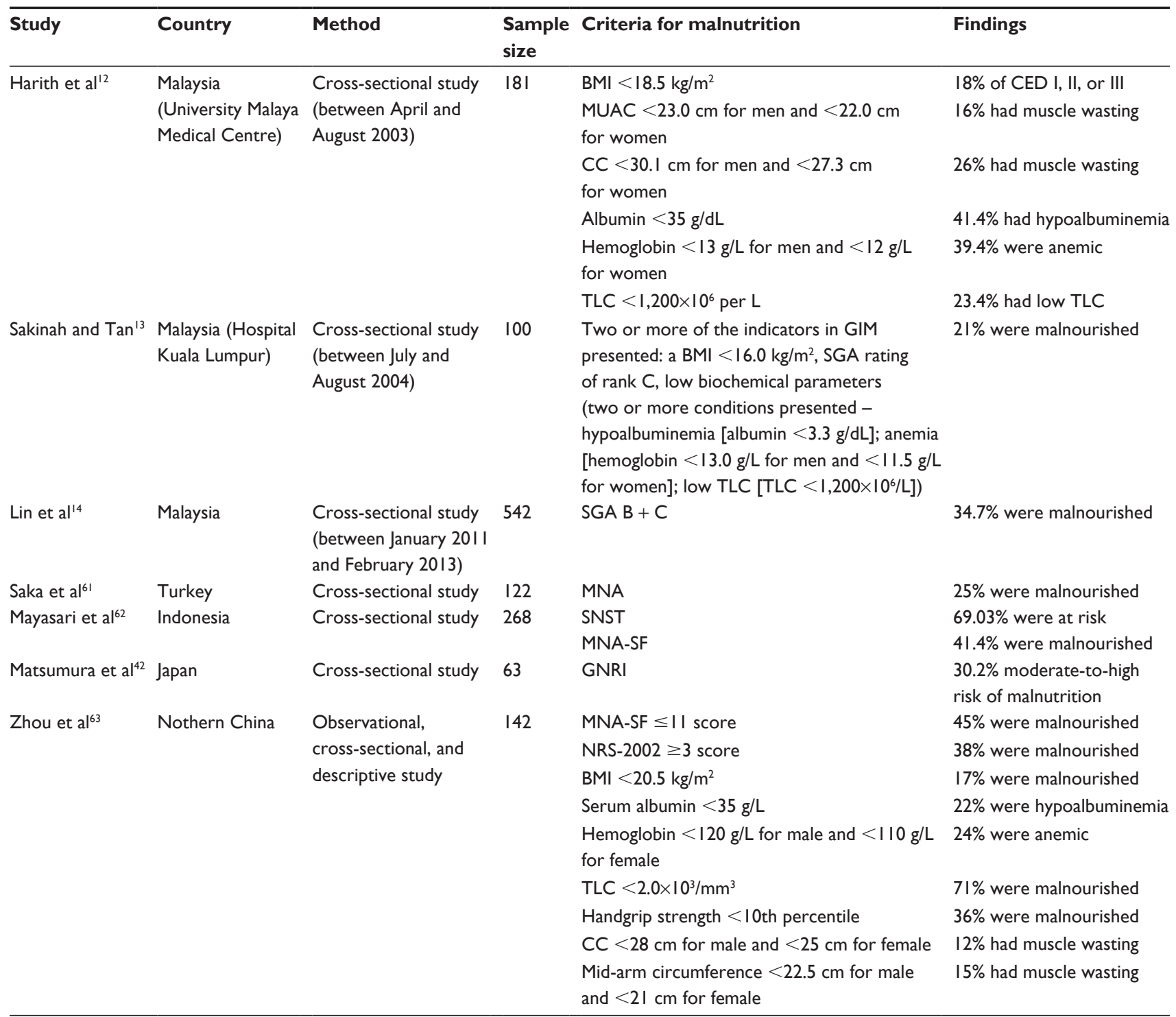

Abbreviations: BMI, body mass index; CED, Chronic Energy Deficiency; MUAC, mid-upper arm circumference; CC, calf circumference; TLC, total lymphocyte count; GIM, Global Indicator of Malnutrition; SGA, Subjective Global Assessment; MNA, Mini Nutritional Assessment; SNST, Simple Nutritional Screening Tool; MNA-SF, Mini Nutritional Assessment Short Form; GNRI, Geriatric Nutrition Risk Index; NRS-2002, Nutritional Risk Screening-2002.

criteria used to identify malnutrition and its risk. Internationally, the prevalence of malnourished hospitalized elderly is ranging from $11 \%$ to $45 \%$, while the latest local data show that the prevalence of hospitalized elderly continues to increase. ${ }^{14}$ Thus, malnutrition is common among hospitalized elderly and has always been underestimated, underdiagnosed, and undertreated, both locally and internationally. Nevertheless, to formulate the health care system and to protect the elderly population from the risk of poor health and malnutrition, evidence-based information on their nutritional status is indeed important. ${ }^{15}$

Awareness on malnutrition among hospitalized elderly is crucial to provide care as its prevalence continues to increase from time to time, and in addition, nutritional care policies should be adapted. Thus, obtaining latest data on prevalence of malnutrition among hospitalized elderly is always important as it can give an overview of the extent to which this issue has currently become a burden to this population. Moreover, the need of health services for this population can be determined if these data are available which can also help in assessing the effectiveness of current actions that are being undertaken. It is believed that this will not only improve the outcome but also ensure a continuum of care and avoid progressive deterioration of nutritional status.

\section{Causes and effects of malnutrition in elderly}

The aging process is believed to be one of the causes of malnutrition, which eventually affect the nutritional status of 
the elderly. ${ }^{7}$ It is also believed that the association between food insecurity and various social, physiological, and health changes that occur with aging is the cause of malnutrition among the elderly population. ${ }^{16}$ The process of aging will cause various body changes, which may or may not affect the nutritional status of the elderly. Common problems faced by this group are the loss of bone density and sarcopenia. Loss of bone density will increase the risk of osteoporosis. Sarcopenia is related to loss of muscle mass that will lead to further accumulation of fat in an individual, and it can be seen even in a healthy person. It can be identified when further assessments are done, whereby loss of strength, functional decline, and poor endurance can be seen in an individual affected with sarcopenia. Furthermore, changes in the digestive system also occur with aging. A reduction in the gastric acid secretion, which causes limited absorption of iron and vitamin B-12 and decreased saliva production, will lead to slower peristalsis and constipation. Sensory changes will lead to dysregulation of appetite and thirst. Sensory changes may also make the food less appealing, and the elderly might have difficulties to cook and eat normally as their vision declines. ${ }^{17}$ These changes may affect the nutritional status of the elderly causing an increase in the risk of falling ill and malnourishment.

Despite these factors, malnutrition itself can be the cause of illness as it is related to many health problems. Malnutrition can lead to poor immune function making an individual prone to infections, poor wound healing, and muscle weakness, which might later cause falls and fractures. Nutritional status of the elderly further deteriorates as malnutrition itself causes further disinterest in eating or lack of appetite. ${ }^{17}$ Generally, malnutrition is caused not only by the process of aging itself but also by the combination of various social, physiological, and health changes that occur with aging, income constraint, limited food insecurity, lack of social contact, and depression. However, malnutrition is still under-recognized, resulting mostly in deprived nutritional status, morbidity, prolonged hospitalization, increased health care cost, and reduced quality of life among the elderly population. ${ }^{16,18,19}$ Thus, management and prevention steps to overcome the deterioration of the health and well-being among the elderly are crucial, and nutritional screening and assessment are important to be carried out.

\section{Nutritional screening and assessment tools}

Accurate identification of malnourished patients using a structured assessment and documentation of the patients' nutritional status will allow sufficient attention and intervention to be given. The demand on this issue has led the researchers to validate better nutritional screening and assessment tools from time to time. Failure to recognize and lack of awareness have resulted in the high prevalence of malnutrition, which leads to poor identification, documentation, and intervention for combating malnutrition, causing prolonged hospitalization due to delayed recovery of the elderly patients. ${ }^{5}$ Tables 3 and 4 show the common nutritional screening and assessment tools used in Asia based on the previous systemic review, respectively. ${ }^{9}$

The nutritional screening and assessment tools presented in Tables 3 and 4, respectively, have been well validated. A nutritional screening tool that has a high sensitivity will allow further diagnosis of malnutrition and appropriate intervention to be done, while a nutritional screening tool with a high specificity will reduce the risk of overtreatment of malnutrition, especially to those who do not need it. ${ }^{13}$ A recent local study had proven that Malnutrition Universal Screening Tool (MUST) has similar validity levels as Malnutrition Screening Tool (MST) among the hospitalized adult patients, but MUST had been shown to have a higher reliability result as compared to MST and it is recommended that MUST should be used in identifying the high-risk malnourished patients. ${ }^{20}$ Malnutrition Risk Screening Tool for Hospital (MRST-H) is however developed locally in 2012, and it shows a moderate sensitivity (0.67) and a high specificity (0.96) using the GIM as the standard reference. ${ }^{21}$ Reevaluation of MRST-H using SGA as the standard reference has been done recently, which covered the general hospital in eight states in the Peninsular Malaysia where it showed similar results. Low sensitivity $(0.12$ and 0.35$)$ and high specificity (1.00 and 0.99 ) of MRST-H have been found in the study, and thus, to improve this, the authors suggested a new MRST-H cutoff score of 2 points instead of the original cut-off score of 5 points to be used in identifying patients who are at risk of malnutrition. This new cutoff score had been shown to have a high area under the curve value in the receiver operating curve analysis $(0.84$ and 0.88$) .{ }^{14}$ The MRST-H using the new cutoff score is recommended as a suitable screening tool for Malaysian hospitalized elderly population.

Meanwhile, in the context of nutritional assessment, SGA and MNA had been listed as the recommended nutritional assessment tool to be used in adults by the Dietitian Association of Australia (DAA). ${ }^{19}$ It is suggested that the elderly should have a full nutritional assessment conducted using a tool, such as MNA or SGA. The elderly who has been screened and has been identified to be at risk of malnutrition will then be referred to a hospital nutrition professional 
Table 3 Common nutritional screening tools for hospitalized elderly used in Asia

\begin{tabular}{|c|c|c|}
\hline Tool & Characteristic of the tool & Result interpretation \\
\hline \multirow[t]{2}{*}{ MST } & Simple, quick, valid, and reliable & $\geq 2$ score $=$ requires further assessment \\
\hline & Have 2 questions on weight reduction and reduced appetite & \\
\hline \multirow[t]{5}{*}{ SNAQ } & Easy, short, valid, and reproducible questionnaire to detect early hospital & $0-I$ point $=$ well nourished \\
\hline & malnutrition & 2 points and nutritional intervention = moderately \\
\hline & Have 3 questions on unintentional weight loss within past $1-6$ months, & malnourished \\
\hline & reduced appetite within past I month, and supplementation usage or & 3 points, nutritional intervention, and treatment by a \\
\hline & tube feeding within past I month & dietitian $=$ severely malnourished \\
\hline \multirow[t]{2}{*}{ MUST } & To screen adult patients & I score $=$ medium risk \\
\hline & $\begin{array}{l}\text { Patients' BMI, percentage of unintended weight loss within past } 6 \text { months, } \\
\text { and estimates of the effect of illness on dietary intake are needed }\end{array}$ & $\geq 2$ score $=$ high risk \\
\hline \multirow[t]{3}{*}{ MRST-H } & $\begin{array}{l}\text { Developed in Malaysia specialized for detection of malnourished elderly } \\
\text { hospitalized patients }\end{array}$ & $\geq 5$ scores $=$ high risk of malnutrition \\
\hline & Have structured questionnaire (eg, physical function, self-feeding, & \\
\hline & unintentional weight loss) and anthropometric measurements & \\
\hline \multirow[t]{4}{*}{ NRS-2002 } & ESPEN recommended to use for nutritional screening in identifying risk & Scoring is based on two components which are \\
\hline & in severely ill patients & $\begin{array}{l}\text { nutrition and disease severity (score of } 0-3 \text { based on } \\
\text { whether these components are absent, mild, moderate, } \\
\text { or severe). The total score ranges from } 0 \text { to } 6 \text {. }\end{array}$ \\
\hline & Consist of parameters which are BMI, recent weight loss, recent & Total score category: ${ }^{64} 0-2=$ well nourished; \\
\hline & decrease in food intake, and severity of illness ${ }^{29}$ & $3-4=$ medium risk; $5-6=$ nutritionally at risk \\
\hline
\end{tabular}

Note: Copyright (C) 2015. Content Ed Net Taiwan Limited. Adapted from Chern CJH, Lee SD. Malnutrition in hospitalized Asian seniors: an issue that calls for action. J Clin Gerontol Geriatr. 2015;6(3):73-77.9

Abbreviations: MST, Malnutrition Screening Tool; SNAQ, Short Nutritional Assessment Questionnaire; MUST, Malnutrition Universal Screening Tool; BMI, body mass index; MRST-H, Malnutrition Risk Screening Tool for Hospital; NRS-2002, Nutritional Risk Screening-2002; ESPEN, European Society for Clinical Nutrition and Metabolism.

for further assessment. ${ }^{9}$ SGA is the common nutritional assessment tool being used in the clinical setting and has been considered as an impressive method to be used as it helps the clinicians identify insignificant changes in clinical variables. ${ }^{22}$ It was found that SGA has a high level of interrater reproducibility with $91 \%$ of surgical patients classified as malnourished by SGA having two clinicians agreeing on their SGA classification. ${ }^{22}$ There is another nutritional tool that has been developed, GNRI. ${ }^{23}$ It is an improved version of Nutrition Risk Index (NRI) that was developed specifically for the elderly population. Its validity has been tested from time to time, but not yet in Malaysia.

A variety of nutritional screening and assessment tools have been developed that share the same purposes, which are to reduce the increasing rate of malnutrition and to avoid its complications. Nutritional screening and assessment

Table 4 Common nutritional assessment tools for hospitalized elderly used in Asia

\begin{tabular}{|c|c|c|}
\hline Tool & Characteristic of the tool & Result interpretation \\
\hline SGA & $\begin{array}{l}\text { A validated tool consists of clinical history (weight loss history, } \\
\text { dietary intake changes, gastrointestinal symptoms persisting } \\
\text { for more than } 2 \text { weeks, and functional capacity) and physical } \\
\text { examination (subcutaneous fat, muscle wasting, ankle and sacral } \\
\text { edema, and ascites) }\end{array}$ & $\begin{array}{l}\text { Based on nutrition rating: SGA A = well-nourished; SGA B = moderate } \\
\text { or suspected undernourished; SGA C = severely undernourished } \\
\text { Some studies use 7-point scale, but the authors of SGA do not } \\
\text { attribute numeric scores to the tool as well as disagree with the } \\
\text { combination of SGA with objective tests in view that it does not seem } \\
\text { to enhance the ability of subjective assessment to predict the presence } \\
\text { of complications associated with malnutrition }{ }^{26}\end{array}$ \\
\hline MNA & $\begin{array}{l}\text { Able to identify multifactorial causes of nutritional risk } \\
\text { specifically in elderly } \\
\text { A questionnaire consisting of } 18 \text { components grouped into four } \\
\text { components which are anthropometry data, general status, } \\
\text { dietary habits, self-perceived health and nutrition states }{ }^{34}\end{array}$ & $\begin{array}{l}\geq 24 \text { scores }=\text { well nourished } \\
17-23.5 \text { scores }=\text { at risk of malnutrition } \\
<17 \text { scores }=\text { malnourished }{ }^{29}\end{array}$ \\
\hline NRI & $\begin{array}{l}\text { An index derived from serum albumin level }(\mathrm{Alb}) \text { and the } \\
\text { ratio of actual-to-usual weight by using following formula: } \\
\mathrm{NRI}=(\mathrm{I} .5 \mathrm{I} 9) \times \mathrm{Alb}(\mathrm{g} / \mathrm{L})+[4 \mathrm{I} .7 \times(\text { present weight/usual } \\
\text { weight })]\end{array}$ & $\begin{array}{l}>100 \text { scores }=\text { well nourished } \\
97.5-100 \text { scores = mildly malnourished } \\
83.5-<97.5 \text { scores = moderately malnourished } \\
<83.5 \text { scores = severely malnourished }\end{array}$ \\
\hline
\end{tabular}

Note: Copyright @ 2015. Content Ed Net Taiwan Limited. Adapted from Chern CJH, Lee SD. Malnutrition in hospitalized Asian seniors: an issue that calls for action. J Clin Gerontol Geriatr. 2015;6(3):73-77.'

Abbreviations: SGA, Subjective Global Assessment; MNA, Mini Nutritional Assessment; NRI, Nutrition Risk Index. 
tools have their own importance and roles in detecting and diagnosing patients with malnutrition; however, this review only discusses the uses of nutritional assessment tools.

\section{Uses of nutritional assessment tools among hospitalized elderly}

Nutrition assessment is a process of obtaining, verifying, and interpreting the data needed to discover the nutrition-related problems, their causes, and significance. ${ }^{24}$ Nutrition assessment is a step that provides the information needed to determine the under- or overnutrition diagnosis and the etiology behind it, and thus, this step is the foundation of the nutritional care process. ${ }^{24}$ Nutritional assessment is usually carried out with the help of a nutrition assessment tool, and the malnourished patients identified by the tool tend to have correlation with multiple complications and prolonged hospital stay. ${ }^{8,22}$ The nutritional tool, consisting of a group of assessments that are commonly performed together, is used by medical staff and registered dietitian nutritionist as a diagnostic tool of malnutrition, and it should be well validated to match the population to which it is applied. ${ }^{24,25}$ The multifactorial causes of malnutrition among the elderly have led the researchers to develop a variety of nutritional assessment tools for early identification of the nutrition problems. However, all health care professionals should note that a nutrition diagnosis does not depend only on a single nutrition assessment finding. ${ }^{24}$ As defined by the ASPEN, nutritional assessment is

a comprehensive approach to diagnosing nutrition problems that use a combination of the following: medical, nutrition, and medication histories; physical examination; anthropometric measurements; and laboratory data. ${ }^{8}$

\section{Subjective Global Assessment}

SGA was developed in the early 1980s by Detsky et al. The European Society for Clinical Nutrition and Metabolism (ESPEN) has recommended it as an acceptable assessment tool, and this tool is widely used among surgical as well as clinical patients. ${ }^{26,27}$ Although it has been developed for the general (adult) hospital population, it is widely used among the elderly. ${ }^{28}$ The DAA also recommends that SGA can be used in all adults, not specifically in the young or elder adults. ${ }^{19}$ SGA is simple, harmless, inexpensive, able to save time, and can be used at the bedside by any health care professional and as well as detect a high nutritional risk; all these advantages have led to the wide clinical use of SGA. However, its accuracy is doubtful whereby the observer's experience is required due to the subjectivity of SGA in detecting the nutritional changes of the patients that may cause the results to be contradictory in a routine health care, especially in teaching hospitals. ${ }^{29}$

Even so, a systemic review had been done recently on SGA in which the authors concluded that SGA is a validated tool for nutritional diagnosis and can be used for the early detection of malnutrition among hospitalized patients. ${ }^{27}$ Based on the systemic review, SGA is valid to be used for assessing the nutritional status of both surgical and clinical patients. Its performance was found to be similar and even superior to the common methods, such as anthropometry and laboratory data. Most studies on SGA proved that it has the ability to correctly assess the nutritional status and predict the risk of postoperative complications over the years. However, the findings were contradictory in the comparative studies. Most of the studies found that other nutritional tools are more suitable to be used than SGA. They suggested to use other nutritional screening tools or recommended to use SGA in combination with other objective methods to improve its performances. In studies on clinical geriatric population, however, SGA showed favorable results in assessing the nutritional status, but most of those studies suggested to use other nutritional tools, such as MUST and MNA, as the first choice in this population. ${ }^{27}$ In Malaysia, SGA is widely used in the hospital setting in all adult populations including geriatric, even though it is not initially developed for this population. Thus, it is crucial to use the nutritional assessment tool that is specifically designed for geriatric population to ensure that the diagnosis of malnutrition is accurate and avoid unnecessary treatment of malnutrition to those who does not need.

\section{Mini Nutritional Assessment}

MNA is the most established nutrition screening and assessment tool for the elderly and a good prognostic tool to detect malnutrition in this group. It was developed in 1994, patented under Nestle, and it is an assessment tool designed specifically for the elderly for assessing malnutrition status. The Mini Nutritional Assessment Short Form (MNA-SF), however, had been designed later to provide a more practical tool in view of the original MNA that might be timeconsuming for screening purposes. MNA-SF consists of six items of the earlier part of the full MNA. It is widely used and is readily available in multiple languages, approximately more than 20 languages, and more than 200 published studies reported on about 35,000 elderly in various settings, including community, home care, hospitals, and much more, using this tool. The tool was shown to have an accuracy 
of $92 \%$ when it was compared with a clinical evaluation by two physicians specialized in nutrition, and $98 \%$ when compared with a comprehensive nutritional assessment, including biochemical tests, anthropometric measurements, and dietary assessment. ${ }^{30,31}$ Many studies had focused on the relationship of MNA with a biochemical test, specifically albumin levels, where some, but not all, had found that there is a correlation of MNA with albumin level probably due to the inflammatory effect of albumin. Total lymphocyte count (TLC), however, was found not to have any relationship with MNA, but lower scores of MNA have a relationship with an impaired immune function. ${ }^{32}$

A previous study in the hospital setting has shown that low scores of MNA can predict poor outcomes, which include prolonged length of stay (LOS), high frequency of discharged patients' visits to nursing homes, and approximately three times increase in mortality. ${ }^{32} \mathrm{MNA}$ is also able to predict the number of drugs administered in both hospitals and nursing homes. In the context of healthy elderly populations, MNA can predict the risk of malnutrition before any changes in serum protein (but not in serum prealbumin levels) occurred, and other visible changes are identified based on the response to the questions on the dietary intake of MNA. The ability of MNA to predict the outcome however varies and is dependent on the care settings. In general, MNA can predict the risk of malnutrition before any significant changes in weight or serum albumin level occurred.

The validity of MNA was proven not only with the anthropometric and biochemical data but also with the body composition data. A study done in the Philippines found that MNA is accurate and reliable in nutritional screening and assessment of Filipino elderly patients, which was proven by the Bioelectrical Impedance Analysis (BIA) data. Malnourished patients identified using MNA showed a comparative BIA data with the BIA data cutoff value $6+$ for elderly with malnutrition. Malnourished patients identified by MNA showed a lower weight (43 kg vs $55 \mathrm{~kg}, P<0.001$ ), BMI (19.5 vs $24, P<0.001$ ), fat weight ( $12 \mathrm{~kg}$ vs $16 \mathrm{~kg}, P=0.001$ ), total body water ( $25 \mathrm{~kg}$ vs $27 \mathrm{~kg}, P=0.005$ ), body cell mass (6 kg vs $9 \mathrm{~kg}, P=0.002)$, and body cell mass percent (13.5\% vs $17 \%, P=0.01)$ and higher total body water percent $(59 \%$ vs $53 \%, P=0.005$ ), and showed no significant difference in fat percent ( $29 \%$ vs $31 \%, P=0.169) .{ }^{33}$ Furthermore, a study in Cairo showed that a high prevalence of malnutrition was identified by MNA accompanied by a reduced functional capacity as determined by using the activity of daily living and instrumental activity of daily living scales. ${ }^{34}$ However, despite these benefits of MNA, the sensitivity is still in doubt because MNA has been related to a high risk of overdiagnosis. ${ }^{28,35}$ Furthermore, the need of caregiver's help to complete MNA, especially for the questions on weight loss, and cognitive or disabilities evaluation, is a limitation in using MNA. ${ }^{36}$ Nevertheless, MNA has been used in most of the studies on the nutritional status of elderly, and it has been recommended to be used as an evidence-based screening tool for the elderly people. ${ }^{37}$

\section{GNRI}

GNRI was developed in 2005 by Bouillanne et al and was designed specifically for the elderly to identify and predict the nutritional-related complications among them. ${ }^{23}$ The validity and reliability of GNRI has been well studied in most countries. ${ }^{36,38,39}$ This tool is modified from the original version, NRI, developed specifically for the hospitalized elderly population. NRI was first introduced by Buzby et al in 1988 to score the severity of the postoperative complications by determining only the patient's weight change and albumin readings. ${ }^{40}$ Since NRI was initially developed for young surgical patients, frequent problems occurred in determining the usual weight of elderly patients; thus, NRI is less reliable to be used among the elderly. ${ }^{41}$ To solve these problems, the GNRI was developed, whereby the usual weight is replaced with the ideal weight as measured by the Lorentz formula. GNRI also uses lower cutoff values for different grades of risk that are associated with nutrition as compared to NRI. ${ }^{23}$ It was designed and cross-validated with the aim to predict morbidity and mortality, which it did well in the design study (odd ratio $>4$ )..$^{28}$

Previous studies have attempted to compare GNRI with other more standardized indices, such as MNA and GNRI, where in both cases, it was found that GNRI is valid to be used among elderly, but mostly in combination with other indices. Nevertheless, most of the authors expressed a similar opinion that further evidence for supporting GNRI validity is still required. ${ }^{41}$ Since then, its validity has been continuously studied across the world including in Cairo and Egypt. Those studies had found that GNRI is more suitable to be used for classifying the nutritional status and identifying nutritional-related complications among hospitalized elderly patients as compared to MNA..$^{38}$

In the aspect of assessing the nutritional status of elderly using GNRI for disease-specific cases, it was found that GNRI is able to predict mortality in hemodialysis patients, has close relationship with exercise tolerance, and is useful to be used as a nutritional assessment scale for COPD among the elderly and able to predict the survival time of the elderly 
patients with esophageal squamous cell carcinoma. ${ }^{42-44}$ GNRI is said to be able to identify potential patients requiring nutritional support, and it appears that GNRI is practical and provides a reliable assessment in most health care settings, particularly for elderly with dementia, aphasia, or apraxia. ${ }^{38}$ A recent cohort study has shown that GNRI has the ability to predict the LOS and in-hospital weight loss, whereby the elderly who were detected as having a nutritional risk by GNRI on admission had the tendency for a prolonged hospital stay and weight loss during hospitalization. ${ }^{45}$ On top of that, it is less time-consuming as well as an easy tool to be used where minimum participation is needed to aid the clinical health care personnel, especially dietitians, to diagnose someone with malnutrition which are some of the added points as to why GNRI is accepted to be used as a tool for assessing the nutritional status of hospitalized elderly.

However, studies on the use of GNRI in Malaysia are very limited, and the validity of GNRI has not yet been evaluated among the elderly Malaysian population. Thus, study of GNRI validity among hospitalized elderly Malaysian population is needed before it is implemented or used in Malaysia. On top of that, MNA is a validated nutritional assessment tool and is widely reported among the elderly in the literature, and thus, a further study to compare the validity of MNA and GNRI, to identify which tool is most suitable to be used in the nutritional assessment process of hospitalized elderly Malaysian population, is suggested. A gold standard to diagnose the elderly with malnutrition is lacking, causing no appropriate treatment to be carried out. ${ }^{46}$ Thus, further study on this matter may help the health care professional, especially the dietitians, to choose the most suitable nutritional assessment tool for the Malaysian population for a better improvement of the NCP to combat malnutrition issue among the hospitalized elderly.

\section{Uses of biochemical parameters among hospitalized elderly}

Determining the nutritional status of the elderly, however, does not only depend on single nutritional parameters. It has to be done in combination with various methods such as anthropometry, biochemical tests, and nutritional screening and assessment. ${ }^{47}$ Simple biochemical parameters such as albumin, hemoglobin, and TLC have long been identified as indicators of the risk of malnutrition-related complications. ${ }^{48-50}$ In Malaysia, studies on validity of nutritional screening tools developed for hospitalized elderly used GIM as the standard reference of malnutrition. ${ }^{13,21}$ GIM is a group of several nutritional assessment measures that are the most commonly accepted standards from the literature. It consists of not only anthropometric measurements (BMI and SGA) but also biochemical parameters (albumin, hemoglobin, and TLC). The patients were considered malnourished if two or more of the indicators in GIM were presented (a BMI $<16.0 \mathrm{~kg} / \mathrm{m}^{2}$, SGA rating of rank $\mathrm{C}$, and low biochemical parameters indicating two or more conditions - hypoalbuminemia, anemia, and low TLC).

Albumin has been widely used as a nutrition marker among other serum proteins synthesized by the liver (transferrin, retinol-binding proteins, and thyroxine-binding prealbumin) due to its ability to predict mortality and other outcomes including perioperative complications in older populations. ${ }^{51,52}$ However, albumin (and other serum proteins synthesized by the liver) is affected not only by nutritional status but as well as by inflammation and infection, which limits its usefulness in acute ill patients. Additionally, the long half-life of albumin limits its usefulness in assessing the short-term changes in both energy and protein intakes. Nevertheless, a study on the use of biochemical parameters in screening the nutritional status of surgical elderly patients suggested to screen albumin level during the patient's early admission to the wards. This will reduce the limitations of the use of albumin in screening those who are at risk of malnutrition. In addition, low hemoglobin level (anemia) was found to be associated with increased mortality risk in elderly, and it has been found that anemia due to malnutrition affects one-third of total elderly populations. This may happen as energy and protein malnutrition causes an increase in the production of cytokines with stimulation of inflammation, immunodeficiency, and anemia. ${ }^{53}$ Low TLC, on the other hand, represents a poor prognosis, and it is associated with low albumin as well. ${ }^{51,54}$ The etiology behind this is that malnutrition causes impairment of immune system and lymphocyte proliferation reduction. ${ }^{54}$

However, out of these simple biochemical markers, there is no single parameter which shows convincing results in the screening test for malnutrition. There is an argument as to whether these simple biochemical parameters reflect the nutritional status or they reflect the state of illness. ${ }^{52}$ A complex biochemical assessment tool has been developed and validated to assess the nutritional status of patient pre-op. ${ }^{55}$ However, the use of this tool in clinical setting is very limited, which causes the important factors of malnutrition to be overlooked. Thus, simple biochemical parameters could be used in detailed assessment and monitoring purposes. ${ }^{52,56}$

\section{Conclusion}

In summary, based on the previous studies, the prevalence of malnutrition among hospitalized elderly shows an increasing 
trend across the world. ${ }^{9-13}$ Underdiagnosis of malnutrition may be the root cause of this problem. However, malnutrition can be identified through nutritional screening and assessment tools. A wide variety of nutritional tools are available nowadays, but they should be reliable, validated, and easy to use. ${ }^{30}$ SGA, MNA, and GNRI are the common validated nutritional assessment tools used among the hospitalized elderly. SGA is, however, not recommended for use in geriatric population as it has low validity to be used among this group, and most studies suggest using nutritional assessment tools developed specifically for elderly. MNA and GNRI have been shown as widely acceptable to be used in the hospital setting. Nonetheless, the results of the studies determining which tool is the best for assessing the nutritional status of this population remain contradictory. The ESPEN recommended to use MNA, but due to low specificity and difficulties in completing the full assessment without the help of caregiver, the use of MNA is limited. GNRI has its own strength on this matter. Its comparable benefits with MNA and its simplicity could help in reducing the time spent on the nutrition assessment process, and thus, a nutrition intervention can be provided as soon as possible to the affected patients. However, studies on the use of GNRI in Malaysia are very limited, and further study on this is suggested. Above all, nutritional status of the hospitalized elderly cannot be determined by only referring to a single nutritional parameter. Thus, simple biochemical parameters such as albumin, hemoglobin, and TLC can be used in combination with nutritional screening and assessment tools to identify those who are malnourished.

\section{Acknowledgments}

The authors thank the anonymous referees for their useful suggestions.

\section{Disclosure}

The authors report no conflicts of interest in this work.

\section{References}

1. United Nations, Department of Economic and Social Affairs, Population Division. World population ageing 2015. United Nations; 2015. Available from: http://www.unpopulation.org. Accessed November 22, 2015.

2. Suzana S Jr, Siti Saifa H. Validation of nutritional screening tools against anthropometric and functional assessments among elderly people in Selangor. Malays J Nutr. 2007;13(1):29-44.

3. Unfpa.org [homepage on the internet]. Ageing. United Nations Population Fund [updated October 13, 2015]. Available from: http://www.unfpa. org/ageing. Accessed November 22, 2015.

4. Phillips MB, Foley AL, Barnard R, Isenring EA, Miller MD. Nutritional screening in community-dwelling older adults: a systematic literature review. Asia Pac J Clin Nutr. 2010;19(3):440-449.

5. Nur Fazimah S, Sakinah H, Rosminah M. Hospitalized geriatric malnutrition: a perspective of prevalence, identification and implications to patient and healthcare cost. Health Environ J. 2013;4(1):55-67.
6. Wells JL, Dumbrell AC. Nutrition and aging: assessment and treatment of compromised nutritional status in frail elderly patients. Clin Interv Aging. 2006;1(1):67-79.

7. Cederholm T, Bosaeus I, Barazzoni R, et al. Diagnostic criteria for malnutrition - an ESPEN Consensus Statement. Clin Nutr. 2015;34(3): $335-340$.

8. Nutritioncare.org [homepage on the internet]. American Society for Parenteral and Enteral Nutrition (ASPEN) Board of Directors and Clinical Practice Committee. Definition of terms, style, and conventions used in A.S.P.E.N. board of directors - approved documents [updated May 2015]. Available from: https://www.nutritioncare.org/WorkArea/ DownloadAsset.aspx?id=3613. Accessed November 22, 2015.

9. Chern CJH, Lee SD. Malnutrition in hospitalized Asian seniors: an issue that calls for action. J Clin Gerontol Geriatr. 2015;6(3):73-77.

10. Corish C, Kennedy NP. Protein-energy undernutrition in hospital inpatients. Br J Nutr. 2000;83(6):575-591.

11. Stratton RJ, King CL, Stroud M, Jackson, Elia M. "Malnutrition Universal Screening Tool" predicts mortality and length of hospital stay in acutely ill elderly. Brit J Nutr. 2006;95(2):325-330.

12. Harith S, Shahar S, Yusoff NAM, Kamaruzzaman SB, Hua PPJ. The magnitude of malnutrition among hospitalized elderly patients in University Malaya Medical Centre. Health Environ J. 2010;1(2):64-72.

13. Sakinah H, Tan SL. Validity of a local nutritional screening tool in hospitalized Malaysian elderly patients. Health Environ J. 2012; 3(3):59-65.

14. Lin TS, Harith S, Abdullah H, Yusuf WNW. Re-evaluation of malnutrition risk screening tool-hospital (MRST-H) for geriatric patients: a multicentre study in Peninsular Malaysia. Sains Malaysiana. 2016; 45(9):1311-1317.

15. Chen ST, Ngoh HJ, Harith S. Prevalence of malnutrition among institutionalized elderly people in Northern Peninsular Malaysia: gender, ethnicity and age-specific. Sains Malaysiana. 2012;41(1):141-148.

16. Shahar S, Ibrahim Z, Fatah AR, et al. A multidimensional assessment of nutritional and health status of rural elderly Malays. Asia Pac J Clin Nutr. 2007;16(2):346-353.

17. Amarya S, Singh K, Sabharwal M. Changes during aging and their association with malnutrition. J Clin Gerontol Geriatr. 2015;6(3): $78-84$.

18. Ożga E, Małgorzewicz S. Ocena stanu odżywienia osób starszych. [Assessment of nutritional status of the elderly]. Geriatria. 2013;7:1-6. Polish [with English abstract].

19. Dietitians Association of Australia Malnutrition Guideline Steering Committee. Evidence based practice guidelines for the nutritional management of malnutrition in adult patients across the continuum of care. Nutr Diet. 2009;66 Suppl 3:S1-S34.

20. Nor Azian MZ, Suzana S, Romzi MA. Sensitivity, specificity, predictive value and inter-rater reliability of malnutrition screening tools in hospitalised adult patients. Mal J Nutr. 2014;20(2):209-219.

21. Sakinah H, Suzana S, Noor Aini MY, Philip Poi JH, Shahrul Bahyah K. Development of a local malnutrition risk screening tool - hospital (MRST-H) for hospitalised elderly patients. Malays J Nutr. 2012;18(2): 137-147.

22. Barker LA, Gout BS, Crowe TC. Hospital malnutrition: prevalence, identification and impact on patients and the healthcare system. Int $J$ Environ Res Public Health. 2011;8(2):514-527.

23. Bouillanne O, Morineau G, Dupont C, et al. Geriatric Nutritional Risk Index: a new index for evaluating at-risk elderly medical patients. Am J Clin Nutr. 2005;82(4):777-783.

24. Field LB, Hand RK. Differentiating malnutrition screening and assessment: a nutrition care process perspective. J Acad Nutr Diet. 2015; 115(5):824-828.

25. Marshall S, Young A, Bauer J, Isenring E. Malnutrition in geriatric rehabilitation: prevalence, patient outcomes, and criterion validity of the scored patient-generated subjective global assessment and the mini nutritional assessment. J Acad Nutr Diet. 2016;116(5):785-794.

26. Detsky AS, McLaughlin JR, Baker JP, et al. What is subjective global assessment of nutritional status? JPEN J Parenter Enteral Nutr. 1987; 11(1):8-13. 
27. da Silva Fink J, Daniel de Mello P, Daniel de Mello E. Subjective global assessment of nutritional status - a systematic review of the literature. Clin Nutr. 2014;34(5):785-792.

28. van Bokhorst-de van der Schueren MA, Guaitoli PR, Jansma EP, de Vet HC. Nutrition screening tools: does one size fit all? A systematic review of screening tools for the hospital setting. Clin Nutr. 2014;33(1): 39-58.

29. Barbosa-Silva MC, Barros AJ. Indications and limitations of the use of subjective global assessment in clinical practice: an update. Curr Opin Clin Nutr Metab Care. 2006;9(3):263-269.

30. Bauer JM, Kaiser MJ, Anthony P, Guigoz Y, Sieber CC. The Mini Nutritional Assessment - its history, today's practice, and future perspectives. Nutr Clin Pract. 2008;23(4):388-396.

31. Cereda E, Pedrolli C, Klersy C, et al. Nutritional status in older persons according to healthcare setting: a systematic review and meta-analysis of prevalence data using MNA ${ }^{\circledR}$. Clin Nutr. 2016;35(6):1282-1290.

32. Anthony PS. Nutrition screening tools for hospitalized patients. Nutr Clin Pract. 2008;23(4):373-382.

33. Francisco EP, Carlos CS, Navarrete DI, Ramos M, Llido LO. Bioelectric Impedance Analysis (BIA) data of Filipino geriatric patients assessed by Mini-Nutritional Assessment (MNA). Poster presented at: 12th Congress of the Parenteral and Enteral Nutrition Society for Asia (PENSA); October 18, 2007; Metro-Manila.

34. Abd-Al-Atty MF, Abou-Hashem RM, Abd Elaziz KM. Functional capacity of recently hospitalized elderly in relation to nutritional status. Eur Geriatr Med. 2012;3(6):356-359.

35. Cereda E. Mini nutritional assessment. Curr Opin Clin Nutr Metab Care. 2012;15(1):29-41.

36. Cereda E, Pedrolli C. The geriatric nutritional risk index. Curr Opin Clin Nutr Metab Care. 2009;12(1):1-7.

37. DiMaria-Ghalili RA. Integrating nutrition in the comprehensive geriatric assessment. Nutr Clin Pract. 2014;29(4):420-427.

38. Abd-El-Gawad WM, Abou-Hashem RM, El Maraghy MO, Amin GE. The validity of Geriatric Nutrition Risk Index: simple tool for prediction of nutritional-related complication of hospitalized elderly patients. Comparison with Mini Nutritional Assessment. Clin Nutr. 2014;33(6): 1108-1116.

39. Komatsu M, Okazaki M, Tsuchiya K, Kawaguchi H, Nitta K. Geriatric nutritional risk index is a simple predictor of mortality in chronic hemodialysis patients. Blood Purif. 2015;39(4):281-287.

40. Buzby GP, Williford WO, Peterson OL, et al. A randomized clinical trial of total parenteral nutrition in malnourished surgical patients: the rationale and impact of previous clinical trials and pilot study on protocol design. Am J Clin Nutr. 1988;47(2 Suppl):357-365.

41. López-Gómez JJ, Calleja-Fernández A, Ballesteros-Pomar MD, et al. Valoración del riesgo nutricional en pacientes ancianos hospitalizados mediante diferentes herramientas. [Screening of the nutritional risk in elderly hospitalized patients with different tools]. Endocrinol Nutr. 2011;58(3):104-111. Spanish [with English abstract].

42. Matsumura T, Mitan Y, Oki Y, et al. Comparison of Geriatric Nutritional Risk Index scores on physical performance among elderly patients with chronic obstructive pulmonary disease. Heart Lung. 2015;44(6): 534-538.

43. Jung YS, You G, Shin HS, Rim H. Relationship between Geriatric Nutritional Risk Index and total lymphocyte count and mortality of hemodialysis patients. Hemodial Int. 2014;18(1):104-112.

44. Bo Y, Wang K, Liu Y, et al. The Geriatric Nutritional Risk Index predicts survival in elderly esophageal squamous cell carcinoma patients with radiotherapy. PLoS One. 2016;11(5):e01559039.

45. Cereda E, Klersy C, Pedrolli C, et al. The Geriatric Nutritional Risk Index predicts hospital length of stay and in-hospital weight loss in elderly patients. Clin Nutr. 2015;34(1):74-78.
46. Jaroch A, Kędziora-Kornatowska K. Nutritional status of frail elderly. Prog Health Sci. 2014;4(2):144-149.

47. Babiarczyk B. Monitorowanie stanu odżywienia osób starszych hospitalizowanych na oddziałach oraz w zakładach opieki krótko- i długoterminowej. [Monitoring of nutritional status in elderly short- and long-term care residents]. Gerontol Pol. 2008;16(1):18-24. Polish [with English abstract].

48. James WP, Ferro-Luzzi A, Waterlow JC. Definition of chronic energy deficiency in adults. Report of a working party of the International Dietary Energy Consultative Group. Eur J Clin Nutr. 1988;42(12): 969-981.

49. Hurwitz J. Interpreting laboratory tests in the elderly. Clin Biochem. $1993 ; 26(6): 433-444$

50. Kamel HK, Karcic E, Karcic A, Barghouti H. Nutritional status of hospitalized elderly: differences between nursing home patients and community-dwelling Patients. Ann Long Term Care. 2000;8:33-38.

51. Alpers DH, Taylor B, Klein S. Approach to the patient requiring nutritional supplementation. In: Tadataka Y, editor. Principles of Clinical Gastroenterology. Oxford: Wiley-Blackwell; 2009:588-623.

52. Basu I, Subramanian P, Prime M, Jowett C, Levack B. The use of biochemical parameters as nutritional screening tools in surgical patients. Surg Sci. 2011;2(2):89-94.

53. Bianchi VE. Role of nutrition on anemia in elderly. Clin Nutr ESPEN. 2016;11:e1-e11.

54. Gariballa S. Nutrition and older people: special considerations relating to nutrition and ageing. Clin Med (Lond). 2004;4(5):411-414.

55. Smith RC, Hartemink R. Improvement of nutritional measures during preoperative parenteral nutrition in patients selected by the prognostic nutritional index: a randomized controlled trial. JPEN J Parenter Enteral Nutr. 1988;12(6):587-591.

56. Ahmed T, Haboubi N. Assessment and management of nutrition in older people and its importance to health. Clin Interv Aging. 2010;5: 207-216.

57. Drescher T, Singler K, Ulrich A, et al. Comparison of two malnutrition risk screening methods (MNA and NRS 2002) and their association with markers of protein malnutrition in geriatric hospitalized patients. Eur J Clin Nutr. 2010;64(8):887-893.

58. Amaral TF, Matos LC, Teixeira MA, Tavares MM, Alvares L, Antunes A. Undernutrition and associated factors among hospitalized patients. Clin Nutr. 2010;29(5):580-585.

59. Vanderwee K, Clays E, Bocquaert I, Gobert M, Folens B, Defloor T. Malnutrition and associated factors in elderly hospital patients: a Belgian cross-sectional, multi-centre study. Clin Nutr. 2010;29(4):469-476.

60. Agarwal E, Ferguson M, Banks M, Bauer J, Capra S, Isenring E. Nutritional status and dietary intake of acute care patients: results from the Nutrition Care Day Survey 2010. Clin Nutr. 2012;31(1):41-47.

61. Saka B, Kaya O, Ozturk GB, Erten N, Karan MA. Malnutrition in the elderly and its relationship with other geriatric syndromes. Clin Nutr. 2010;29(6):745-748.

62. Mayasari M, Susetyowati, Lestariana W. Simple nutritional screening tool (SNST) has good validity to identify risk of malnutrition on hospitalized elderly patients. Pakistan J Nutr. 2014;13(10):573-578.

63. Zhou J, Wang M, Wang H, Chi Q. Comparison of two nutrition assessment tools in surgical elderly inpatients in Northern China. Nutr J. $2015 ; 14: 68$.

64. Koren-Hakim T, Weiss A, Hershkovitz A, et al. Comparing the adequacy of the MNA-SF, NRS-2002 and MUST nutritional tools in assessing malnutrition in hip fracture operated elderly patients. Clin Nutr. 2016;35(5):1053-1058. 
Clinical Interventions in Aging

\section{Publish your work in this journal}

Clinical Interventions in Aging is an international, peer-reviewed journal focusing on evidence-based reports on the value or lack thereof of treatments intended to prevent or delay the onset of maladaptive correlates of aging in human beings. This journal is indexed on PubMed Central, MedLine,

CAS, Scopus and the Elsevier Bibliographic databases. The manuscript management system is completely online and includes a very quick and fair peer-review system, which is all easy to use. Visit http://www.dovepress. $\mathrm{com} /$ testimonials.php to read real quotes from published authors.

Submit your manuscript here: http://www.dovepress.com/clinical-interventions-in-aging-journal 